\title{
A percepção do professor sobre os efeitos da música no comportamento dos alunos
}

\section{Teacher's perception about the effects of music in the students behaviour}

\section{I donézia Collodel Benetti*}

Universidade Federal de Santa Catarina - UFSC, Florianópolis, Santa Catarina, Brasil

\section{Edla Gisard**}

Centro Universitário Municipal de São J osé - USJ, São José, Santa Catarina, Brasil

\section{Luciana Mendes da Silva***}

Universidade do Planalto Catarinense - UNIPLAC, Lages, Santa Catarina, Brasil

\begin{abstract}
RESUMO
Esta pesquisa objetivou verificar se a música provoca mudança de comportamentos internalizantes e externalizantes, no contexto de sala de aula. Foram realizadas dezessete intervenções com duas turmas - uma turma experimental e outra de controle - do segundo ano do ensino fundamental de uma escola pública em uma cidade do Alto Vale do Itajaí (SC). No grupo experimental, as crianças tiveram contato com a letra e a melodia da música nas brincadeiras e exercícios e no grupo de controle foi usado somente o texto. Foi utilizado o CBCL na versão para professores, aplicado antes e após as intervenções. Os resultados obtidos não validaram a $\mathrm{H}_{1}$ da pesquisa, que afirmava existir diferença no comportamento de crianças que tiveram a música como mediadora dos comportamentos internalizantes e externalizantes na sala. Porém, apesar desses níveis não serem considerados significativos, os escores de todos os domínios investigados na pesquisa aumentaram, com exceção dos domínios relacionados aos problemas somáticos e problemas sociais. Hipóteses várias foram buscadas na literatura para justificar os objetivos não alcançados, tais como: a frequência das intervenções, tempo de investigação, ritmo e andamento da musica utilizada, etc.
\end{abstract}

Palavras-chave: música, comportamento, externalização, internalização.

\begin{abstract}
The present research aimed at verifying if music provokes changes in internalizing and externalizing behaviors in classroom contexts. Seventeen interventions were applied with two groups of students - an experimental one and the control group - at the second grade in a public school in the region of Alto Vale do Itajaí (SC). In the experimental group, children had contact with the lyrics and the melody during the activities and the classroom exercises, while in the control group they only had contact with the lyrics. CBCL (teacher's version) was the instrument carried out by the regular teacher, before and after the interventions. The final results did not
\end{abstract}


validate the $\mathrm{H}_{1}$ of the research, which asserted the existing difference among children with internalizing and externalizing behaviour, when they have music as a mediator inside classroom. However, although the levels are not considered significant, the scores of all domains investigated in research increased, except for fields related to somatic and social problems. Several different hypotheses were searched in the field of literature in order to justify the unreached objectives, such as: frequency of the interventions, research time, rhythm and music tempo, etc.

Keywords: music, behavior, externalizing, internalizing.

\section{Notas iniciais}

Sabe-se que dificuldades comportamentais são frequentemente identificadas no contexto escolar. Os comportamentos disruptivos dos alunos, por serem os que provavelmente, apresentam maior visibilidade, constituem preocupação para o corpo escolar. Estes comportamentos têm aumentado, influenciando não só o processo de ensino-aprendizagem - com tendências à apresentação de complicações acadêmicas - mas também as relações interpessoais que, em muitos casos apresentam déficit em habilidades e baixa competência social, respondendo de maneira a promover interações socialmente indesejadas e até negativas, na perspectiva da interação organismo-ambiente.

Neste contexto, a responsabilidade pelo comportamento inadequado na sala de aula e, muitas vezes pelo fracasso escolar, tem recaído sobre os ombros dos alunos. Tais fenômenos geralmente são responsáveis também pela falta de motivação e baixa autoestima e consequente evasão das instituições de ensino, o que acaba deixando a criança em uma posição desfavorável tanto na situação educacional quanto social (Santos \& Graminha, 2005). Além de comportamentos disruptivos, a escola serve de palco para muitas outras manifestações comportamentais tais como: retraimento, irritação, inquietude, dificuldade para fazer amizades, birras, hostilidade etc.

Portanto, há que se pensar em novas estratégias para o processo de ensino/aprendizagem. Para isso, é importante que os educadores e responsáveis pelas crianças estejam atentos a essas dificuldades e se mantenham envolvidos no processo educativo. Uma das técnicas apontadas por esta pesquisa foi o uso da música na tentativa de proporcionar mudanças de comportamento no contexto escolar, mais precisamente na sala de aula.

O principal objetivo foi verificar se a música pode influenciar os comportamentos internalizantes (depressão, ansiedade, retraimento social e queixas somáticas, entre outros), e externalizantes (conflitos com o ambiente, agressividade, impulsividade e comportamento delinquente) das crianças e, dessa forma, contribuir para um processo de ensino/aprendizagem menos preconceituoso, 
se considerarmos o fato de que, em muitos casos, a criança é estigmatizada como incapaz e problemática e, por vezes, rotulada como portadora de deficiências, apenas por apresentar comportamentos socialmente indesejáveis (Neves \& MarinhoAraujo, 2006).

Sacks (2007), em seu livro Alucinações Musicais, expressa que a música é um estímulo fundamental na vida dos seres humanos, e esta se apresenta o tempo todo na vida dos mesmos. Portanto, é relevante estudar o impacto da relação entre música e comportamento, nas duas instâncias previamente mencionadas.

Existem canções para todos os tipos de sentimentos e emoções, e estas possibilitam mais vitalidade, beleza e força para a imaginação e as experiências da criança. Além disso, a música provoca alterações fisiológicas aos que estão de alguma forma em contato com ela, uma vez que tem ação direta sobre o corpo, podendo baixar a pressão sanguínea, aumentar os batimentos cardíacos, alterar a respiração, o desconforto, a tolerância à dor, fazer chorar ou rir, de maneira consciente ou não (Bréscia, 2003).

Diante do exposto, vale frisar que a principal intenção ao desenvolver esta pesquisa foi verificar se a música pode, também, provocar mudanças no comportamento das crianças em sala de aula, levando em consideração que as mudanças físicas podem favorecer mudanças comportamentais (Papalia, Olds \& Feldman, 2006). Vale salientar que, nesse campo de estudo, são poucos os trabalhos empíricos. Há, também, pouca literatura na área, o que justifica a relevância desse trabalho.

\section{Contexto teórico}

A perspectiva bioecológica do desenvolvimento humano (Bronfenbrenner, 2002) leva em consideração os contextos de desenvolvimento do ser humano, formado por estruturas denominadas microssistema, mesossistema, exossistema e macrossistema. No microssistema, são consideradas as relações interpessoais mais próximas do indivíduo. É o ambiente em que a pessoa em desenvolvimento vive experiências pessoais diretas: família, creche e escola; neste ambiente, através dos processos proximais, o desenvolvimento é produzido e sustentado.

O mesossistema é o conjunto de vários microssistemas, incluindo as inter-relações e influências entre dois ou mais ambientes em que o indivíduo está inserido. A participação multiambiente, de acordo com o mesmo autor, é a forma mais básica de interconexão entre dois ou mais ambientes e ocorre quando um indivíduo participa de mais de um ambiente. 
Porém, quando há ligação indireta, o vinculo é intermediário, pois há a participação de uma terceira pessoa entre os ambientes, e a pessoa em desenvolvimento não participa ativamente de ambos os ambientes; apenas está ligada a eles por esta terceira pessoa. Bronfenbrenner (2002) define esse contexto como exossistema onde a pessoa em desenvolvimento não se encontra presente, mas as relações que acontecem entre esses ambientes afetam 0 desenvolvimento. Exemplo disso são as relações de trabalho dos pais, as diretrizes elaboradas e as decisões tomadas pelas autoridades escolares, etc.

Finalmente, o macrossistema, é considerado como a consistência observada dentro de uma cultura, na forma e conteúdo de seus micro, meso e exossistemas, tornando extensivo o sistema de valores e crenças que permeiam a existência das diversas culturas, vivenciando-as e assimilando-as ao longo do desenvolvimento. Vale salientar que esses sistemas estão inter-relacionados dinamicamente durante todo o processo de desenvolvimento (Bronfenbrenner, 2002). Diante do exposto, clara está a importância e o papel que a escola, enquanto microssistema, representa no desenvolvimento das crianças e, portanto, precisa estar preparada no sentido de possibilitar as condições necessárias para que as mesmas possam vivenciar experiências e desenvolver-se, já que é um microssistema que favorece as relações proximais de aprendizagem. Além disso, estimula o desenvolvimento da comunicação, da cultura e dos pensamentos complexos, que estão diretamente ligados ao cérebro, um órgão capaz de refazer sua atividade neural, proporcionando mudança de comportamento, que resulta da experiência vivida (Gazzaniga, 2005).

Essa capacidade do cérebro é denominada plasticidade neural e pode ser definida como mudança adaptativa na estrutura e nas funções do sistema nervoso. Em outras palavras, é a capacidade que o organismo possui de se adaptar às mudanças internas e externas. Dessa forma, indivíduos e ambientes (micro, meso, exo e macrossistema) estão interligados contingentemente e, sendo assim, os comportamentos emitidos pelo indivíduo dependerão dos estímulos que o mesmo receberá do(s) ambiente(s) (Ferrari, Toyoda, Faleiros \& Cerutti, 2001).

Em sintonia com os autores previamente citados, Vygotsky (1994) enfatiza a importância que o ambiente exerce sobre nossas reações comportamentais. Indo um pouco mais além, estudos em neurociência têm comprovado que os ambientes físico e social provocam a atividade das células neurais que, uma vez ativadas, resultam em comportamento (Ferrari et al., 2001). Essas relações interfuncionais do cérebro dependem, portanto, das influências fornecidas pelo meio exterior - micro, meso, exo e microssistemas. 
Os estudos de Vygotsky (1994) e Bronfenbrenner (2002) mostram que o desenvolvimento é alcançado a partir da interação com o ambiente, e, portanto, é imprescindível o auxilio de um adulto como mediador no processo de desenvolvimento infantil, atuando como "intérprete" entre a criança e o meio em que está inserida.

Dentro dos estudos pertinentes ao contexto social e escolar, a importância do comportamento dos alunos tem sido devidamente estudada como componente de aporte para o desenvolvimento social e emocional, para a adaptação e ajustamento ao microssistema escolar, para a aprendizagem e, consequentemente, para o sucesso acadêmico (Agostin \& Bain, 1997).

Os comportamentos humanos, produto da relação cérebro-meio ambiente, estão classificados em duas categorias: comportamentos internalizantes (Isolamento, Queixas Somáticas e Ansiedade/Depressão) e externalizantes - Agressividade e Quebra de Regras (Achenbach \& Edelbrock, 1979). Em linhas gerais, são manifestações marcadas por déficits ou excedentes comportamentais que prejudicam a convivência com os colegas e com os adultos presentes no seu cotidiano e no seu contexto.

Os termos "Internalização" e "Externalização", na perspectiva de Wangby, Bergman e Magnusson (1999), são significados utilizados para albergar problemas que envolvem conflitos com o ambiente. Externalizantes são consideradas as manifestações de agressividade, impulsividade e de comportamentos anti-sociais - transtorno de conduta e transtorno desafiador opositivo - para problemas que afetam o estado psicológico/interno/privado da criança, em contraste com os problemas relacionados ao mundo externo, portanto ao contexto/ambiente. Internalizantes são manifestações associadas à depressão, ansiedade, retraimento social e queixas somáticas transtornos do humor e transtornos de ansiedade. Tanto os comportamentos internalizantes quanto externalizantes são afetados e afetam, principalmente, os micro, meso, e exossistemas.

Nesta linha de pensamento, comportamentos marcados por agressividade - física ou verbal - impulsividade, hiperatividade, oposição, destrutividade, desobediência, teimosia, acesso de raiva, e manifestações anti-sociais são classificados como externalizantes (Ferreira \& Marturano, 2002). Ainda, podem aparecer como atos de cometer furtos, mentir, faltar aula, desrespeitar os limites, envolverse em brigas, ser provocador e agressivo nos relacionamentos (Achenbach \& Edelbrock, 1979; Bolsoni-Silva, Silveira, \& Ribeiro, 2008b).

Vale enfatizar que a literatura apresenta uma preocupação mais acentuada, por parte de pais e professores, com a emissão de comportamentos extenalizantes, por perturbarem e alterarem os microssistemas onde são produzidos e demandarem mais atenção e 
cuidados, no momento de fazer a contenção de tais ações (Barreto, Del Prette, Del Prette \& Magalhães, 2006).

Além destas preocupações, os comportamentos externalizantes têm sido apontados (Betz, 1995) como fator de risco para a delinquência juvenil precoce, o crime e a violência, sendo, portanto, considerados como um problema de saúde pública (Campbell, Harris, \& Lee, 1995; Harm, 2002). Dentro deste prisma, não são surpreendentes as pressões sociais relacionadas à prevenção da violência, com a finalidade de trazer equilíbrio para os sistemas afetados por esse fenômeno.

Os comportamentos externalizantes são mais estáveis, no sentido de que, uma vez adquiridos, são mais difíceis de serem modificados, tendo curso e prognóstico menos favoráveis, especialmente os comportamentos de agressividade, impulsividade e tendências antisociais, mais frequentes e persistentes na infância, e precursores dos distúrbios de conduta na adolescência (Ferreira \& Marturano, 2002).

É importante ressaltar que os comportamentos externalizantes, como componentes anti-sociais, são frequentemente desenvolvidos em contextos de adversidade ambiental. Os estudos, para verificar a origem desses comportamentos, têm mostrado que as manifestações externalizantes refletem processos de trocas contínuas entre as características das crianças nas interações sociais com as características dos cuidadores e seu contexto social (Olson, Bates, Sandy, \& Lanthier, 2000). Nessas trocas, a criança está exposta a um ambiente familiar marcado por práticas violentas de socialização, modelos adultos agressivos, falta de afeto materno e conflito entre os pais, e estes comportamentos estão associados a um contexto social adverso com dificuldades econômicas e estressores psicossociais (Mcloyd, 1988). Em contrapartida, os comportamentos internalizantes podem ser manifestos através de preocupações exageradas, tristeza, timidez, insegurança, manifestações psicossomáticas e recuso escolar (Bolsoni-Silva, Carrara, \& Marturano, 2008a). Considerando que, em muitos casos, é no microssistema escolar que os comportamentos alcançam maior visibilidade, os comportamentos internalizantes, muitas vezes, não chamam a atenção dos professores, por passarem despercebidos, e o aluno é visto como desanimado e quieto (Lyra, Assis, Njaine, Oliveira \& Pires, 2009).

Esses comportamentos, além de representar graves e crônicas consequências para as crianças, podem influenciar o microssistema familiar, escolar, etc., incluindo, nestas esferas, os pais, irmãos, professores, colegas e sociedade em geral. Assim, as crianças correm o risco de sofrer rejeição pelos companheiros, gerar conflitos em família e com professores, protagonizar o fracasso escolar e correr riscos mais sérios para comportamentos socialmente desviantes (Olson et al., 2000). 
Os comportamentos internalizantes podem ter, também, impactos negativos na inter-relação microssistema-pessoa incluindo professores, pais, irmãos e colegas. De igual maneira, os comportamentos externalizantes não afetam negativamente apenas o microssistema, mas podem trazer sofrimento psicológico para quem os emite. Em outras palavras, uma criança agressiva pode experimentar comportamentos internalizantes como ansiedade, por exemplo, e uma criança depressiva pode apresentar comportamentos anti-sociais (Achenbach \& Edelbrock, 1979).

Resumindo, os estímulos ambientais e a relação pessoa-ambiente são fundamentais para que o desenvolvimento humano aconteça. No caso da escola, as crianças interagindo naquele espaço, a maneira como o professor lida com a rotina deste contexto de desenvolvimento, tudo o que é sentido, vivido e produzido ali, certamente contribui para o bem estar ou mal estar de todos os que participam deste microssistema e, consequentemente, se estende aos outros microssistemas em que a criança se insere.

Assim, tendo a escola como um dos principais contextos de desenvolvimento das crianças, as investigações sobre comportamentos, nesta pesquisa, são baseadas, principalmente, nos relatos do professor, pois o mesmo tem contato direto de observação sobre elas, sendo apontado como um avaliador digno de confiança, no que se refere ao comportamento de seus alunos no ambiente escolar (Santos \& Graminha, 2005).

\section{Música e comportamento}

Pode-se dizer que a exposição e o contato auditivo com o som, a menos que se tenha alguma restrição auditiva, é inevitável, pois o som está em toda parte. Em todas as sociedades e culturas as canções de ninar estão presentes na vida dos bebês, sendo estas cantadas rotineiramente por seus cuidadores (Trehub \& Trainor, 1998). No caso de crianças pré-escolares ou em idade escolar, elas se utilizam por vezes das canções durante as brincadeiras ou inventam suas próprias músicas no decorrer dessas brincadeiras (Rosa, 1990).

A investigação científica dos aspectos e processos psicológicos ligados à música, na opinião de Bréscia (2003), é tão antiga quanto às origens da psicologia como ciência. O interesse pela psicologia da música e, consequentemente, as várias áreas, que surgiram desse interesse, deram origem também a áreas mais relacionadas ao desenvolvimento e ao ensino-aprendizagem. A música provoca as mais diversas reações no indivíduo e seus efeitos psicológicos positivos, no que diz respeito à agressividade, são ilustrados: 
Ziggiatti (2001) se refere ao emprego de músicas de Mozart, Bach e Beethoven em West Palm Beach Flórida, EUA, como instrumento na luta contra o crime, informando que as autoridades instalaram um alto-falante que transmitia vinte e quatro horas de música desses três compositores numa esquina conhecida como ponto de ladrões e traficantes. Verificou-se uma redução de cento e dezenove para oitenta e três no número de denúncias recebidas pela polícia, tendo como base o índice de dois anos consecutivos antes e depois da introdução da música no local (Bréscia, 2003, p. 62).

Certamente, este é um dos motivos pelo qual a arte, em especial a música, se faz necessária no microssistema escolar, por proporcionar aos alunos um crescimento nos domínios da autoestima, capacidade simbólica e competência de fazer julgamentos, além da constituição de um pensamento flexível (Blood \& Zatorre, 2001), o que pode influenciar nos comportamentos internalizantes e externalizantes dos alunos em sala de aula - microssistema responsável pelo ensino/aprendizagem sistematizados.

Além disso, os mesmos autores advogam que a música ativa a parte cerebral responsável pelo sistema de recompensa - Circuito de Recompensa Cerebral (situado no sistema límbico) - e da emoção, localizado no hemisfério direito, proporcionando respostas de prazer e conforto para os que estejam expostos aos seus acordes. Além disso, - lado direito do cérebro trabalha com os aspectos emocionais e criativos como artes, música e imaginação, enquanto o lado esquerdo governa as habilidades analíticas como falar, pensar, julgar, ler e escrever e, dessa forma, os dois lados do cérebro se complementam. Dois eixos de aprendizagem são proporcionados pela música: o eixo horizontal e o vertical, sendo que o eixo horizontal diz respeito às atitudes tomadas pelas crianças frente aos outros; como exemplo, pode-se citar a interação, trocas de experiências e conversas. Já o eixo vertical refere-se aos sentimentos, emoções e ansiedades da criança, tendo a funcionalidade de agente motivador (Stevick, 1971). Infelizmente, o uso da arte muitas vezes tem sido empregado como instrumento decorativo, sem serem explorados seus múltiplos sentidos, a criação do imaginário, a provocação de movimentos e mudanças, etc. No contexto escolar, com certa frequência, o uso da música como instrumento mediador do processo ensino/aprendizagem tem sido apresentado timidamente, ou negligenciado (Almeida, 2007, citado por Romanelli, 2009, p. 38).

Projetos e iniciativas maiores ligados à música têm sofrido menosprezo e até mesmo exclusão por parte da política educacional brasileira (macrossistema), tanto dentro como fora do contexto escolar, apesar de que as crianças encontram grande prazer com a expressão de suas emoções por meio da voz. Considere-se também o 
fato de que as cantigas de roda ou cirandas proporcionam união, alegria, sintonia, afeto, amizade, ternura e amor (Bréscia, 2003).

Entre as diversas linguagens artísticas, a música tem um papel fundamental na escola, pois é um veículo facilitador da construção do conhecimento e da formação de um sujeito autônomo diante do mundo sonoro no qual vive, capaz de fazer suas escolhas musicais, além de se tornar sensível aos estímulos que esta arte pode oferecer. Assim, a música, quando usada para mediar comportamento, além de todos esses benefícios, exerce um papel importante nas relações interpessoais (Ilari, 2006). A música "é a arte que mais se aproxima da criança" e é um dos meios mais eficazes de educação dos sentidos, desenvolvendo a sensibilidade, a emoção, a compaixão e a receptividade (Ribas, 2003, citado por Campos, 2006, p. 43).

De acordo com Rosa (1990, p. 19), “A música é uma linguagem expressiva e as canções são vínculos de emoções e sentimentos e podem fazer com que a criança reconheça nelas seu próprio sentir". Bréscia (2003) advoga que o ato de cantar se constitui em um grande aliado da aprendizagem, pois traz como consequência a contribuição na socialização e na aprendizagem de conceitos e descoberta do mundo sendo, portanto, um veículo de memorização, compreensão, e expressão das emoções.

Nesse cenário, a música contém ingredientes de promoção de desenvolvimento humano, reunindo os aspectos globais (físico, mental, social, emocional e espiritual) e constituindo-se, também, em um veículo facilitador da aprendizagem sistemática, favorecendo o bem-estar dos educandos. Mesmo não sendo foco de investigação, mas para preparar o caminho para ela, o desenvolvimento das intervenções também envolveu o ato de:

- planejar e preparar um ambiente de aprendizagem promotor de iniciativas, exploração ativa de material, e engajamento sustentado com o outro (crianças e adultos presentes no microssistema escolar); - selecionar materiais adequados ao nível de desenvolvimento e origens culturais das crianças (Bronfenbrenner, 2002);

- incentivar a competência linguística e a comunicação das crianças;

- apoiar o uso de atividades lúdicas e incentivar as brincadeiras, promovendo estratégias de ensino envolvendo a interação;

- oferecer oportunidades para as crianças a fim de que elas planejem, pensem, reflitam e discutam suas próprias experiências.

\section{Considerações sobre o método}

Esta pesquisa apresenta uma modalidade que está sendo cada vez mais utilizada pela psicologia: a pesquisa interventiva que, diferente da pesquisa-ação e da pesquisa participante, tem como objetivos dar 
ênfase aos aspectos psicológicos tanto na aplicação da proposta quanto no conhecimento dos participantes, nas relações estabelecidas entre participantes e pesquisadores e também na compreensão, análise e exposição do conhecimento produzido (Baptista, Noguchi, \& Calil, 2006). Além disso, tem como finalidade produzir conhecimento científico, através de atuações realizadas junto a um grupo ou comunidade.

É, também, uma pesquisa de cunho quase-experimental (Campbell \& Stanley 1979), uma vez que apresenta: a) identificação de variáveis - dependente e independente, b) comparação entre grupos: grupo controle e grupo experimental, c) exclusão de variáveis que possam interferir no estudo, d) aplicação de pré e pós teste em ambos os grupos, e e) generalização a partir dos dados alcançados.

\subsection{Contexto e participantes}

Os participantes da pesquisa são estudantes de uma escola pública de uma cidade situada no Alto Vale do Itajaí, com idade entre sete e nove anos e média de idade de oito anos, com desvio padrão de 0,83 - sendo 14 do período matutino e 12 do período vespertino. Do grupo experimental, participaram seis meninos e oito meninas e, do outro grupo, sete meninos e cinco meninas. A professora regular, responsável por responder ao instrumento da pesquisa e por fazer anotações em um diário de campo, atua na rede estadual há aproximadamente treze anos e tem formação no ensino superior. Aos 34 anos de idade, ela trabalha nessa unidade escolar há aproximadamente 9 anos.

A região da escola escolhida para a coleta de dados é culturalmente italiana e alemã. A principal fonte de renda das famílias das crianças participantes é baseada no comércio, no setor metal-mecânico e eletrônico e, principalmente, na confecção de jeans. Essas famílias possuem baixo poder aquisitivo, o que justifica a frequência em escolas da rede pública.

\subsection{Procedimentos}

Após aprovação do comitê de ética da universidade local e permissão da direção da unidade escolar e das professoras de duas turmas do segundo ano (uma do grupo experimental e a do grupo controle), o Termo de Consentimento Livre e Esclarecido (TCLE) foi assinado pelos pais autorizando a participação de seus filhos neste estudo.

A pesquisa foi efetuada em dezessete encontros consecutivos, na unidade escolar, respeitando-se os finais de semanas. A duração de cada encontro foi de uma hora e meia, onde eram trabalhados os conteúdos de letramento pela pesquisadora, que utilizou a música (letra e melodia), com a intenção de avaliar a participação e o 
envolvimento das crianças nas atividades escolares, nesse caso a leitura com a utilização da música.

As intervenções tiveram como base a música e seu texto como ponto de partida para a pesquisa com comportamento, tendo a acadêmica recebido treinamento para realizar as intervenções. Durante o processo interventivo, houve alteração na organização da sala de aula - as carteiras foram arranjadas em círculo. A pesquisadora assumiu as aulas referentes às dezessete intervenções, quando foram utilizadas técnicas para o reconhecimento de letras, palavras e frases.

As atividades eram lúdicas, envolvendo bingo, substituição de letras com o alfabeto móvel, reconhecimento de palavras iguais, reconhecimento de palavras com sentidos opostos, combinação de sílabas, rimas, classificação de palavras, organização de sentenças na ordem lógica, adivinhas, ovelha negra - atividade que consiste em achar o 'diferente', o que não se enquadra no contexto proposto etc.

Essas atividades foram produzidas de acordo com a letra da música escolhida e as crianças do grupo experimental aprenderam a música (melodia e letra), paralelamente às tarefas desenvolvidas em sala. As crianças do grupo controle tiveram os mesmos conteúdos e as mesmas tarefas, porém sem a presença da música (melodia), mas com a presença da letra.

Para efeito de minimização de varáveis intervenientes, as turmas escolhidas tinham a mesma professora regular e a mesma pesquisadora, que, na tentativa de isolar tais variáveis, utilizou o mesmo procedimento tanto na turma experimental quanto na turma controle, com exceção do CD com a música, que foi usado apenas na turma experimental.

Também, antes que se iniciasse o processo interventivo, a pesquisadora, com a finalidade de familiarizar-se com os microssistemas escolhidos para a pesquisa, frequentou, durante uma semana, por três dias alternados, as aulas da professora regular. Esse procedimento aproximou a pesquisadora das crianças, na tentativa de evitar estranhamentos.

A professora regular não participou das atividades desenvolvidas pela acadêmica-pesquisadora, ficando apenas na posição de observadora. Porém foi solicitado a ela que tivesse um caderno para anotar e descrever as possíveis mudanças de comportamento, como um instrumento extra para corroborar e ilustrar com qualidade e fidedignidade os dados obtidos. Essas anotações foram realizadas durante as intervenções.

Para verificar o impacto da música nos comportamentos internalizantes e externalizantes das crianças em sala de aula, foi feito o uso do "Teste/Reteste" utilizando o CBCL (Child Behavior Checklist), antes do início das atividades interventivas (teste) e ao 
final das mesmas (reteste). Os questionários foram respondidos pela professora regular dos dois grupos - experimental e controle.

Por participarem do desenvolvimento escolar da criança, são creditadas aos professores condições de mostrar seu ponto de vista em relação ao comportamento apresentado pela criança no microssistema escolar. A pesquisadora também elaborou um diário de campo, onde registrou o comportamento das crianças, percebidos em cada intervenção. Os registros foram efetuados após cada intervenção.

O diário de campo foi concebido como instrumento de suma importância para a revisitação, comparação e reflexão sobre os resultados quantitativos. Fragmentos dos registros nele contidos foram analisados, sendo verificados sua pertinência e sentidos possíveis, decorrentes do trabalho de comparação e análise. Tudo o que foi capturado e registrado pode ser, então, confrontado com as respostas ao CBCL.

\subsection{Instrumento de avaliação}

Com o objetivo de chegar a um resultado de pesquisa mais confiável, foi utilizado o CBCL (Child Behavior Checklist) um instrumento de avaliação criado por Achenback, nos Estados unidos, no final da década de setenta e validado no Brasil por Bordin, Mari e Caeiro (1995). Este instrumento tem como objetivo medir o grau de competência social e os problemas comportamentais de crianças e adolescentes, na percepção dos pais ou cuidadores (Santos \& Silvares, 2006).

Faz parte do CBCL o Teacher's Report Form (TRF), que é um questionário para ser preenchido por professores, ou outros profissionais da educação, sobre comportamentos internalizantes e externalizantes de crianças, baseando-se nos últimos dois meses.

A Escala de Competência Social mede o envolvimento da criança em atividades diversas, tais como: brincadeiras, jogos, execução de tarefas, bem como a participação em grupos, relacionamento com pessoas (familiares, amigos), independência no brincar e desempenho escolar, etc. (Bordin et al., 1995). Outras escalas são de Ansiedade/Depressão, Isolamento/Depressão, Queixas Somáticas, Problemas Sociais, Problemas de Pensamento, Problemas de Atenção, Comportamento de Quebrar Regras/Delinquencial e Comportamento Agressivo (Silvares, Meyer, Santos, \& Gerencer, 2006). Como opções de resposta, são apresentadas as seguintes alternativas: falsa, pouco verdadeira/às vezes verdadeira, muito verdadeira/frequentemente verdadeira.

Como recurso extra, todas as atividades pedagógicas, pedidas para serem realizadas, pelas crianças, no microssistema familiar, foram recolhidas, com a finalidade de verificar seu comportamento quanto 
ao envolvimento com as tarefas de casa - se havia interesse no cumprimento dessas tarefas e responsabilidade na sua devolução. Além disso, as professoras das turmas anotaram, em um diário de campo, o comportamento das crianças, onde foram feitas breves descrições de cada intervenção e foram registrados os comportamentos que mais chamavam a atenção das professoras durante as aulas interventivas.

As anotações e as tarefas serviram como complemento para entender os resultados do CBCL. No caso desta pesquisa, auxiliou para a compreensão das razões pelas quais os objetivos não foram alcançados. Os dados, provenientes do $\mathrm{CBCL}$, foram analisados através do programa estatístico SPSS, versão 15, com o objetivo de realizar análises estatísticas descritivas e análises de associação entre as variáveis apresentadas e os grupos pesquisados.

\section{Resultados encontrados}

Os resultados deste trabalho são oriundos da opinião e da percepção, principalmente, da professora regular e da pesquisadora dos dois grupos estudados, que auxiliaram a formar um quadro abrangente do comportamento dos alunos. A opinião foi gerada a partir de informação disponibilizada pelos dados e pelas estatísticas - análise do teste/reteste e do engajamento na realização das tarefas de casa. A percepção esteve baseada na observação dos comportamentos em sala de aula - relacionamento com os pares, com a pesquisadora, envolvimento e aceitação das intervenções, aceitação - registrada no CBCL e no diário de campo.

Esperava-se, com essa pesquisa, provocar mudanças nos comportamentos internalizantes e externalizantes dos sujeitos que estiveram sob as atividades interventivas apresentadas neste estudo. A tabela 1 mostra os resultados para os dados pareados das crianças que tiveram a música (texto e melodia) como mediadora nas intervenções. Pode-se perceber que, embora os níveis não sejam considerados significativos, os escores de todos os domínios investigados na pesquisa aumentaram, com exceção dos domínios relacionados aos problemas somáticos e problemas sociais, os quais não apresentaram nenhuma alteração na média.

Tabela 1 - Comparação entre médias: grupo experimental antes e após as intervenções 
Idonézia Collodel Benetti, Edla Gisard, Luciana Mendes da Silva A percepção do professor sobre os efeitos da música no comportamento dos alunos

\begin{tabular}{|c|c|c|c|c|c|c|}
\hline & & $\mathrm{N}$ & Média & $\begin{array}{l}\text { Desvio } \\
\text { padrão }\end{array}$ & $\mathrm{t}$ & $\begin{array}{l}\text { Nível de } \\
\text { Significãncia }\end{array}$ \\
\hline \multirow{2}{*}{$\begin{array}{l}\text { Pareação } \\
1\end{array}$} & Ansiedade & \multirow{2}{*}{12} & 2,42 & 4,35 & \multirow[t]{2}{*}{,867 } & \multirow[t]{2}{*}{, $000^{* *}$} \\
\hline & Ansiedade (pós) & & 2,92 & 5,01 & & \\
\hline \multirow{2}{*}{$\begin{array}{l}\text { Pareação } \\
2\end{array}$} & Isolamento & \multirow{2}{*}{12} & 1,25 & 2,34 & \multirow[t]{2}{*}{,941 } & \multirow[t]{2}{*}{, $000^{\star *}$} \\
\hline & Isolamente (pós) & & 1,58 & 3,47 & & \\
\hline \multirow{2}{*}{$\begin{array}{l}\text { Pareação } \\
3\end{array}$} & Problemas Somáticos & \multirow{2}{*}{12} &, 50 & 1,16 & \multirow[t]{2}{*}{808} & \multirow[t]{2}{*}{, $001^{* *}$} \\
\hline & Problem. Somátic. (pós) & &, 50 & 1,44 & & \\
\hline \multirow{2}{*}{$\begin{array}{l}\text { Pareação } \\
4\end{array}$} & Problemas Sociais & \multirow{2}{*}{12} & 1,83 & 4,36 & \multirow[t]{2}{*}{,986 } & \multirow[t]{2}{*}{, $000 * *$} \\
\hline & Problemas sociais (pós) & & 1,83 & 3,68 & & \\
\hline \multirow{2}{*}{$\begin{array}{l}\text { Pareação } \\
5\end{array}$} & Problemas de Pensamento & \multirow{2}{*}{12} & ,83 & 2,32 & \multirow[t]{2}{*}{, 513} & \multirow[t]{2}{*}{, 088} \\
\hline & Problem. de Pensam. (pós) & & 1,00 & 2,13 & & \\
\hline \multirow{2}{*}{$\begin{array}{l}\text { Pareação } \\
6\end{array}$} & Problemas de Atenção & \multirow{2}{*}{12} & 7,25 & 9,49 & \multirow[t]{2}{*}{,966 } & \multirow[t]{2}{*}{, $000 * *$} \\
\hline & Problem. de Aten. (pós) & & 8,08 & 10,08 & & \\
\hline \multirow{2}{*}{$\begin{array}{l}\text { Pareação } \\
7\end{array}$} & Quebra Regras & \multirow{2}{*}{12} & ,83 & 2,58 & \multirow[t]{2}{*}{,351 } & \multirow[t]{2}{*}{,263 } \\
\hline & Quebra regras (pós) & & ,92 & 1,08 & & \\
\hline \multirow{2}{*}{$\begin{array}{l}\text { Pareação } \\
8\end{array}$} & Agressividade & \multirow{2}{*}{12} & 2,75 & 5,69 & \multirow{2}{*}{,855 } & \multirow{2}{*}{, $000 * *$} \\
\hline & Agressividade (pós) & & 2,92 & 3,91 & & \\
\hline \multirow{2}{*}{$\begin{array}{l}\text { Pareação } \\
9\end{array}$} & Total de Problemas & \multirow{2}{*}{12} & 18,00 & 30,79 & & \\
\hline & Total (pós) & & 19,08 & 29,11 & ,980 &, $000 * *$ \\
\hline
\end{tabular}

${ }^{* *} \mathrm{p} \leq 0,001$

Ao comparar os escores obtidos no grupo experimental, a tabela 1 revela o pareamento dos dados encontrados no teste - re-teste. Com base nos dados da tabela, observa-se que há crescimento significativo em quase todas as variáveis avaliadas antes e depois. Os níveis de significância encontrados na maioria das comparações mostraram-se com níveis de $p \leq 0,001$.

A tabela 2 sinaliza a correlação dos dados estatísticos pareados das crianças que não tiveram a música (melodia) como mediadora nas intervenções. Os dados apontam que houve diminuição dos escores relativos à média, em todos os domínios investigados, quando somente o texto da música foi apresentado. A correlação e o t (pareação 3) não puderam ser computados, porque a diferença do erro de desvio padrão é zero. 
Idonézia Collodel Benetti, Edla Gisard, Luciana Mendes da Silva A percepção do professor sobre os efeitos da música no comportamento dos alunos

Tabela 2 - Comparação entre médias: grupo controle - antes e após as intervenções

\begin{tabular}{|c|c|c|c|c|c|c|}
\hline & & $\mathrm{N}$ & Média & $\begin{array}{l}\text { Desvio } \\
\text { padrão }\end{array}$ & $\mathrm{t}$ & $\begin{array}{l}\text { Nivel } \\
\text { Significancia }\end{array}$ \\
\hline \multirow{2}{*}{$\begin{array}{l}\text { Pareação } \\
1\end{array}$} & Ansiedade & 14 &, 43 & ,756 & & \\
\hline & Ansiedade (pós) & & ,00 & ,000 & & - \\
\hline \multirow{2}{*}{$\begin{array}{l}\text { Pareação } \\
2\end{array}$} & Isolamento & 14 & ,29 & ,611 &,- 135 & ,647 \\
\hline & Isolamento (pós) & & 14 &, 535 & & \\
\hline \multirow{2}{*}{$\begin{array}{l}\text { Pareação } \\
3\end{array}$} & Problemas Somáticos & 14 &, $00(a)$ & ,000 & - & - \\
\hline & Problemas Somáticos (pós) & &, $00(a)$ &, 000 & & \\
\hline \multirow{2}{*}{$\begin{array}{l}\text { Pareação } \\
4\end{array}$} & Problemas Sociais & 14 & ,36 & 1,082 & 171 &, 559 \\
\hline & Problemas sociais (pós) & & 14 &, 535 & & \\
\hline \multirow{2}{*}{$\begin{array}{l}\text { Pareação } \\
5\end{array}$} & Problemas de Pensamento & 14 & ,14 & ,363 & ,113 & ,700 \\
\hline & Problem. de Pensam. (pós) & & 07 & ,267 & & \\
\hline \multirow{2}{*}{$\begin{array}{l}\text { Pareação } \\
6\end{array}$} & Problemas de Atenção & 14 & 3,93 & 4,104 & ,466 & ,093 \\
\hline & Problem. de Atenção (pós) & & 3,07 & 3,100 & & \\
\hline \multirow{2}{*}{$\begin{array}{l}\text { Pareação } \\
7\end{array}$} & Quebra Regras & 14 & ,36 & 1,082 & 171 &, 559 \\
\hline & Quebra regras (pós) & &, 07 &, 267 & & \\
\hline \multirow{2}{*}{$\begin{array}{l}\text { Pareação } \\
8\end{array}$} & Agressividade & 14 & 1,21 & 3,984 & ,980 &, $000 * *$ \\
\hline & Agressividade (pós) & & ,36 & 1,082 & & \\
\hline \multirow{2}{*}{$\begin{array}{l}\text { Pareação } \\
9\end{array}$} & Total de Problemas & 14 & 6,93 & 10,774 &, 405 & ,150 \\
\hline & Total (pós) & & 3,93 & 4,649 & & \\
\hline
\end{tabular}

Observando os dados apresentados da tabela 2, percebe-se apenas uma diferença entre grupos com significância estatística aproximada de $p \leq 0,001$, no domínio agressividade. As demais diferenças entre os dados pareados não se mostraram estatisticamente significativas. As tarefas de casa, solicitadas pela acadêmica-pesquisadora, como forma de auxílio para consolidação de conhecimentos e, também, para verificar o envolvimento dos alunos, não teve, a principio, o retorno esperado. Porém, à medida que as intervenções progrediam mais e mais crianças do grupo experimental traziam suas tarefas, confirmando, no mínimo, mais envolvimento com as atividades extras, quando comparado com o início dos trabalhos e com as crianças do grupo controle. 


\section{Discussão}

Como as hipóteses aventadas para a pesquisa não foram comprovadas, é possível tecer algumas considerações reflexivas sobre os dados apresentados. Sempre ancorado no contexto (Bronfenbrenner, 2002), este trabalho visa contribuir, também, para apontar caminhos para novas investigações e questionamentos nesta área, com o objetivo de alcançar resultados mais significativos, do ponto de vista estatístico.

Dentro dessa linha de pensamento, uma hipótese para o fato de não ter havido modificação estatisticamente significante nos padrões comportamentais após as intervenções pode residir no fato de que as 17 intervenções foram realizadas de maneira intensiva, diariamente, contrariando as intervenções apresentadas na literatura da área (Bolsoni-Silva et al., 2008c; Bolsoni-Silva, Silveira, \& Ribeiro, 2008b; Gonçalves \& Murta, 2008) que, usualmente, são realizadas, no máximo, duas vezes por semana.

Vale salientar, também, que os autores previamente citados operacionalizaram procedimentos envolvendo $\mathrm{O} C B C L$ - algumas pesquisas com menos de 17 intervenções - e durante um período de investigação mais longo, com intervalo de tempo entre as intervenções, o que parece oferecer mais chances de modificação de comportamento. Neste sentido, surge a seguinte pergunta: será que este projeto teria maiores ganhos se ocorresse por um período mais longo de tempo, ou seja, por alguns meses e não semanas tendo três intervenções semanais, em vez de cinco?

Uma segunda hipótese, atrelada à primeira, está baseada nos escritos de Siddons e Lancaster (2004), que apontam para o fato de que o(s) mesmo(s) informante(s) tende(m) a comunicar menos problemas da primeira para a segunda avaliação, o que não se verifica da segunda para a terceira avaliação. Surge, assim, a segunda pergunta: seria o caso de fazer uma terceira aplicação do $\mathrm{CBCL}$, para verificar se houve mudanças de comportamento?

Dentro das hipóteses, com as quais podem justificar-se a não validação das propostas desenhadas para esta pesquisa, pode estar o fato de que a música tem a função de aumentar ou diminuir o estado de excitação de seus ouvintes (Bréscia, 2003; Gregory, 1997). De acordo com estes autores, tanto o ritmo quanto o andamento tendem a influenciar o comportando. A música lenta tem função de relaxamento, enquanto a música rápida serve para aumentar o estado de excitação.

Dentro deste quadro, a música usada - um forró nordestino - se encaixa dentro da proposta de andamento e ritmo rápidos, podendo ser categorizada, então, como excitante. Os gêneros musicais que se enquadram neste estilo tendem, de acordo com alguns pesquisadores (Bréscia, 2003; Vasconcelos, 2004) a aumentar a pressão sanguínea, 
promovendo a excitação fisiológica e contribuindo, em muitos casos, para comportamentos inadequados. Nesta perspectiva, esta pesquisa faz surgir mais uma dúvida: teria sido o ritmo e o andamento da música escolhida parcialmente responsável pelo resultado que mostrou que os sujeitos da pesquisa continuaram agitados?

As crianças do grupo experimental se mostravam mais felizes e por vezes eufóricas. Uma possível explicação, além de a música utilizada ser um forró, é que as intervenções aconteciam após o intervalo do lanche, o que pode ter estendido o tempo de agitação das crianças durante a execução das intervenções, que foram realizadas após a pausa costumeira para o recreio, sofrendo influência dos eventos ocorridos nos microssistema (Bronfenbrenner, 2002).

Identificar as principais formas de ocorrência de manifestações comportamentais das crianças na sala de aula poderia representar a elaboração de estratégias, instrumentos e procedimentos que facilitassem uma melhor adaptação das crianças no contexto escolar. Porém, essas estratégias e procedimentos, de acordo com os resultados desta pesquisa, não foram significativamente validadas, tendo com mediação este gênero musical.

Indo um pouco mais além, vale lembrar que na pesquisa de Ziggiatti (1999), citado por Bréscia, 2003) o uso da música como instrumento na luta contra o crime, contou com o gênero clássico e encontrou redução de 119 para 83 no número de denúncias recebidas pela polícia, comprovando os efeitos positivos da música com relação à agressividade. Tompson (2009), utilizando a música clássica, obteve resultados positivos com relação à capacidade de expressar-se das crianças. Essas se anunciavam de forma menos inibida quando eram submetidas a sessões musicais.

Então, na tentativa de entender as razões para a não comprovação da $\mathrm{H}_{1}$ desta pesquisa, que afirmava existir diferença no comportamento de crianças que têm a música como mediadora dos comportamentos internalizantes e externalizantes na sala de aula, vale salientar que a presente investigação trabalhou com uma música com ritmo de forró, sendo este gênero musical considerado acelerado/agitado.

O que pode ser observado, também, no grupo experimental, a partir do ponto de vista da acadêmica-pesquisadora, ainda que em um caso isolado, foi a presença de duas crianças que nas primeiras intervenções estavam sempre chorando e se recusavam a participar das brincadeiras e exercícios, mas que a partir da quarta intervenção, começaram a participar sempre mais, mostravam-se sempre alegres e dispostas a fazer as atividades e a ajudar nas brincadeiras. Além disso, ainda pediam para escrever no quadro e distribuir os materiais utilizados entre os colegas. Esses comportamentos sugerem que a música tenha possibilitado uma aliança entre a pesquisadora e as crianças. 
Dentro do quadro de comportamentos, essenciais para o ajustamento e o sucesso na escola, estão as atitudes de pedir ajuda, perguntar e responder, estabelecer relações interpessoais e de amizades, iniciar, manter e terminar uma interlocução (Del Prette \& Del Prette, 2005). Ao longo das intervenções pode-se também observar a mudança em favor destes comportamentos. Na primeira intervenção, as crianças do grupo experimental estavam muito agitadas: empurravam-se, agrediam-se verbalmente, desrespeitavam a pesquisadora com comentários do tipo "que música chata, que exercício chato", pisavam nas figuras, e caíam no chão propositalmente. Com o avanço do processo interventivo, as crianças deste grupo estavam mais tranquilas e envolvidas, e faziam comentários diferentes dos anteriores: "que bom que você veio professora, o que faremos hoje?" "Podemos fazer um circulo?" Este comportamento pode explicar 0 aumento no nível de ansiedade positiva das crianças.

A música ativa a parte cerebral responsável pelo sistema de recompensa e emoção, ocasionando respostas de prazer e conforto a quem está ouvindo (Blood \& Zatorre, 2001). As crianças do grupo experimental se mostravam muito interessadas, sempre recebendo a pesquisadora com alegria e entusiasmo. Exemplo disso é que, ao voltar na sala de aula uma semana depois, todas as crianças a abraçavam e perguntavam se haveria mais intervenções, declarando estarem com saudades e algumas cantando trechos da música, diferentemente do grupo de controle que, nas últimas intervenções, se mostravam cansados e pareciam sem vontade de participar das atividades.

Compactuando com a teoria bioecológica de Bronfenbrenner (2002), quando inserimos a criança em um novo microssistema, há mudanças de padrões comportamentais por inclusão de estímulos e processos proximais, que são definidas por ele como as interações "entre um organismo humano biopsicológicoativo em evolução e as pessoas, objetos e símbolos em seu ambiente imediato". Neste sentido, a execução do projeto proporcionou aos alunos um microssistema novo, um contexto diferente daquele a que os mesmos estavam acostumados, o que pode justificar as mudanças de comportamentos citados acima.

Na perspectiva de Bronfenbrenner (2002), é no microssistema que a pessoa em desenvolvimento vivencia suas experiências pessoais, alcançando e sustentando o desenvolvimento através dos processos proximais. Assim, outra hipótese para o aumento da ansiedade é o fato de que, ao entrar na sala de aula propondo uma nova dinâmica de aprendizagem, a pesquisadora provocou mudanças no microssistema das crianças. Indivíduos e ambientes estão interligados contingentemente e, sendo assim, os comportamentos emitidos pelo indivíduo dependerão dos estímulos que o mesmo receberá do ambiente (Bronfenbrenner, 2002; Ferrari et al., 2001). 
Portanto, o fato de o nível de ansiedade ter aumentado pode estar ligado aos estímulos oferecidos às crianças do grupo experimental. Vale salientar que o grupo controle, a partir dos dados do $C B C L$, não sofreu aumento da ansiedade, o que sugere que a principal responsável tenha sido a música - melodia - pois esta pode ter provocado maior impacto no microssistema das crianças.

Shenfield, Trehub, e Nakata (2003) perceberam benefícios cognitivos em curto prazo ao expor crianças às canções de ninar, cantadas por suas mães. Essa exposição aumentou o nível de atenção e interesse das crianças mais do que quando estiveram expostas apenas a episódios da fala materna. As crianças desempenharam melhor as tarefas, estando alertas e contentes. Isso também pode ser observado nesta pesquisa. No decorrer das intervenções, ao serem expostas à música, a cada dia as crianças se mostravam mais envolvidas no processo, estando mais participativas e menos dispersas. Observou-se, ainda, mais comprometimento com as tarefas de casa. Assim, seria possível assumir que a música é um excelente instrumento de mediação no comportamento das mesmas, enquanto inseridas no microssistema sala de aula no ensino fundamental.

\section{Notas finais}

Por se tratar de uma área nova a ser pesquisada, e por não ter na literatura muitos exemplos de métodos a serem seguidos, foi encontrada dificuldade no que diz respeito aos tipos de métodos a se utilizar para avaliar e também para se aplicar em um estudo desta natureza, o que pode explicar o fato de que as expectativas da pesquisa não tenham sido alcançadas.

Porém, apesar de que os resultados quantitativos tenham revelado mudanças de comportamentos contrárias às expectativas da pesquisa, um olhar para os registros realizados nos diários de campo - da professora regular e da acadêmica-pesquisadora - mostra que, ao longo das intervenções, o interesse pelas atividades, nas crianças do grupo experimental, cresceu, diferentemente das crianças do grupo controle, pois foram observados comentários do tipo: "Que música chata" (grupo controle) e "Oba! Podemos fazer um círculo?" Ou ainda: "Professora eu quero uma cópia desse CD" (grupo experimental). No grupo controle, confirmando o que já vinha sendo observado, os comentários nas últimas intervenções foram: "Hoje é o último dia?" "Quando será o último dia?" "Eu não gosto de fazer círculo".

Observou-se ainda que, mesmo depois de alguns dias, ao voltar na sala para falar com a professora, as crianças do grupo experimental demonstravam sentimento de afeto para com a pesquisadora e as 
ofensas verbais entre si passaram a ocorrer com frequência cada vez menor, à medida que as intervenções progrediam. Foi possível perceber que ocorria frequentemente ajuda mútua entre as crianças, o que não acontecia com a turma que não tinha a melodia da música como mediadora.

Neste grupo, elas se mostravam mais irritadas com o passar das intervenções, e as agressões verbais aconteciam com mais frequência nos últimos encontros, em comparação aos primeiros. O interesse pelas dinâmicas pareceu também ter diminuído, já que algumas crianças se negavam a participar, enquanto outras tinham a expressão de cansaço.

Poderíamos deduzir, então, que a música é um recurso mediador importante nas relações afetivas e/ou sociais. Porém, diante dos resultados desta pesquisa, fazer tal afirmação com base apenas nos dados e observações torna-se muito arriscado. Por esta razão, sugerem-se novas investigações nesta área, a fim de identificar o que há de melhor na música para ser aplicado com crianças no contexto escolar, uma vez que, no que se refere a pesquisas que correlacionem música e comportamentos inadequados, a literatura permanece escassa, principalmente no Brasil.

Assim, dada a divergência dos dados quantitativos com relação aos registros de campo, é prudente que mais pesquisadores se engajem na produção de pesquisas e literatura na área psicossocial envolvendo este tema que, conforme antes assinalado, é muito carente de pesquisas empíricas. Há necessidade de se empreender mais esforços para realizar novas pesquisas, que utilizem novos métodos, a fim de comprovar resultados, sejam eles os esperados ou não.

\section{Referências}

Achenbach, T. M., \& Edelbrock, C. S. (1979). The child behavior profile: II. Boys aged $12-16$ and girls aged 6-11 and 12-16. Journal of Consulting and Clinical Psychology, 47(2), 223-233.

Agostin, T. M., \& Bain, S. K. (1997). Predicting early school success with developmental and social skills screeners. Psychology in the Schools, 34(3), 219-228.

Baptista, M. T. D. S., Noguchi, N. F. C., \& Calil, S. D. B. W. (2006). A pesquisa interventiva na psicologia: análise de três experiências. Psicologia para a América Latina, 7(12), 55-63.

Barreto, S. O., Del Prette, Z. A. P., Del Prette, A., \& Magalhães, T. (2006). Concomitância, dificuldades de aprendizagem e problemas de comportamento: Análise descritiva da ocorrência de problemas de comportamento, em crianças, segundo 
avaliação do professor. In Anais da 58a Reunião Anual da SBPC. Florianópolis: UFSC.

Betz C. L. (1995). Childhood violence: A nursing concern. Issues in Comprehensive Pediatric Nursing, 18, 149-161.

Blood, A. J., \& Zatorre, R. J. (2001). Intensely pleasurable responses to music correlate with activity in brain regions implicated in reward and emotion. Proceedings of the National Academy of Sciences, 98(20), 1118-11123.

Bolsoni-Silva, A. T., Carrara, M., \& Marturano, E. M. (2008a) Intervenção em grupo para pais: a importância do diagnóstico comportamental individual. In R. Cavalcanti (Org.), Análise do Comportamento: Avaliação e intervenção (pp. 79-100). São Paulo: Roca.

Bolsoni-Silva, A., Salina-Brandão, A., V., Fabiana M., \& Rosin-Pinola, A. R.(2008c). Avaliação de um programa de intervenção de habilidades sociais educativas parentais: um estudo-piloto. Psicologia: Ciência e Profissão, 28(1), 18-33.

Bolsoni-Silva, A. T.; Silveira, F. F., \& Ribeiro, D. C. (2008b). Avaliação dos efeitos de uma intervenção com mães/cuidadoras: contribuições do treinamento em habilidades sociais. Contextos Clínicos, 1(1), 19-27.

Bordin, I. A. S., Mari, J. J., \& Caeiro, M. F. (1995). Validação da versão brasileira do Child Behavior Checklist (CBCL) Inventário de Comportamento da Infância e da Adolescência: dados preliminares. Revista ABP - APAL, 17(2), 55-66.

Bréscia, V. L. P. (2003). Educação Musical: bases psicológicas e ação preventiva. São Paulo: Átomo.

Bronfenbrenner, U. (2002). Ecologia do desenvolvimento humano: Experimentos naturais e planejados. Porto Alegre: Artmed.

Campos, D.C. (2006). Música, neuropsicologia e transtorno do déficit de atenção/hiperatividade (TDAH): diálogo entre Arte e Saúde. In XVI Congresso da Associação Nacional de Pesquisa e PósGraduação em Música (ANPPOM). Brasília: ANPPOM.

Campbell, J.C., Harris, M. J., \& Lee, R. K. (1995). Violence research: An overview. Scholarly Inquiry for Nursing Practice, 9, 105-126.

Campbell, D.T., \& Stanley, J.C. (1979). Delineamentos experimentais e quase-experimentais de pesquisa. São Paulo: EPU-EDUSP.

Del Prette, Z. A. P., \& Del Prette, A. (2005). Habilidades Sociais na infância: teoria e prática. Petropólis: Vozes.

Ferrari, E. A. M., Toyoda, M. S. S., Faleiros, L., \& Cerutti, S. M. (2001). Plasticidade Neural: Relações com o Comportamento e Abordagens Experimentais. Psicologia: teoria e Pesquisa, 17(2), 187- 194.

Ferreira M.C.T., \& Marturano, E. M. (2002). Ambiente familiar e os problemas do comportamento apresentados por crianças com 
baixo desempenho escolar. Psicologia: reflexão e crítica, 15(1), 35- 44.

Gazzaniga, M. S. (2005). Ciência Psicológica: mente, cérebro e comportamento. Porto alegre: Artmed.

Gonçalves, E. S., \& Murta, S. G. (2008). Avaliação dos efeitos de uma modalidade de treinamento de habilidades sociais para crianças. Psicologia Reflexão e Crítica, 21(3), 430-436.

Gregory, A. H. (1997). The roles of music in society: the ethnomusicological perspective. In D. J. Hargreaves, \& A. C. North (OrgS.), The social psychology of music (pp.123-140). Oxford: Oxford University Press.

Harm, D.M. (2002). Taking stock of risk factors for child/youth externalizing behavior problems. Bethesda: National Institute of Mental Health.

Ilari, B. (2006). Música, comportamento social e relações interpessoais. Psicologia em estudo, 11(1), 191-198.

Lyra, G. F. D., Assis, S. G., Njaine, K., Oliveira, R. V. C., \& Pires, T. O. (2009). A relação entre professores com sofrimento psíquico e crianças escolares com problemas de comportamento. Ciências e saúde coletiva, 14(2), 235-444.

Mcloyd, C. (1988). Socioeconomic disadvantage and child development. American Psychologist, 53(2), 185-204.

Neves, M. M. B. J., \& Marinho-Araujo, C. M. (2006). A questão das dificuldades de aprendizagem e o atendimento psicológico às queixas escolares. Alethéia, 24(2), 161-170.

Olson, S. L., Bates, J. E., Sandy, J. M., \& Lanthier, R. (2000). Early developmental precursors of externalizing behavior in middle childhood and adolescence. Journal of Abnormal Child Psychology, 28(2), 119-133.

Papalia, D. E., Olds, S. W., \& Feldman, R.D. (2006). Desenvolvimento Humano. Porto Alegre: Artmed.

Romanelli, G. (2009). O espaço da música nas séries iniciais do ensino fundamental e sua mediação pelo professor unidocente. In Semana de Ensino pesquisa e extensão de Educação. Paraná, UFPR.

Rosa, N. S. S. (1990). Educação musical para 1ạ a 4a SÉRIE. São Paulo: Ática.

Sacks, O. (2007). Alucinações Musicais: relatos sobre a música e o cérebro. São Paulo: Campainha das Letras.

Santos, P. L., \& Graminha, S. S. V. (2005). Problemas Emocionais e Comportamentais Associados ao Baixo Rendimento Acadêmico. Revista Estudos de Psicologia, 11(1), 101-109.

Santos, E. O. L., \& Silvares, E. F. M. (2006). Crianças enuréticas e crianças encaminhadas para clínicas-escola: Um estudo comparativo da percepção de seus pais. Psicologia Reflexão e Crítica, 19(2), 277-282. 
Shenfield, T., Trehub, S. E., \& Nakata, T. (2003). Maternal singing modulates infant arousal. Psychology of Music, 31(4), 365-375.

Siddons, H., \& Lancaster, S. (2004). An overview of the use of the Child behavior Checklist within Australia. Australia: Accerpress.

Silvares, E. F. M., Meyer, S. B., Santos, E. O. L., \& Gerencer, T. T. (2006). Um Estudo em Cinco Clínicas-Escolas Brasileiras com a Lista de Verificação Comportamental para Crianças (CBCL). In E.F.M. Silvares, Atendimento Psicológico em Clínicas-Escola. Campinas: Editora Alíneas.

Stevick, E. W. (1971). Adapting and Writing Language Lessons. Washington: Foreign Service Institute.

Tompson, W. F. (2009). Music, thought, and feeling: understanding the psychology of music. Oxford: Oxford University Press.

Trehub, S., \& Trainor, L. (1988). Singing to Infants: Lullabies and Play Songs. Advances in Infant Research, 12, 43-77.

Vasconcelos, T. C. (2004). Personalidade, valores e condutas antisociais de jovens. Dissertação de Mestrado, Departamento de Psicologia, Universidade Federal da Paraíba, João Pessoa.

Vygotsky, L. S. (1994). A formação social da mente: o desenvolvimento dos processos psicológicos superiores. São Paulo: Martins Fontes.

Wangby, M., Bergman, L., \& Magnusson, D. (1999). Development of adjustment problems in girls: What syndromes emerge? Child Development, 70(3), 678-699.

\section{Endereço para correspondência \\ I donézia Collodel Benetti}

Universidade Federal de Santa Catarina

Centro de Filosofia e Ciências Humanas - Campus Universitário, Trindade, CEP 88040-600, Florianópolis - SC, Brasil

Endereço eletrônico: idonezia@hotmail.com

\section{Edla Gisard}

Universidade de São J osé

Rua Koesa, 305, Kobrasol, CEP 88102-310, São José - SC, Brasil

Endereço eletrônico: edlagrisard@gmail.com

\section{Luciana Mendes da Silva}

Avenida Castelo Branco, 170, Bairro Universitário, CEP 88511-040, Lages - SC, Brasil

Endereço eletrônico: lumendesphn@hotmail.com

Recebido em: 08/03/2013

Reformulado em: 28/01/2014

Aceito para publicação em: 02/02/2014

\section{Notas}

* Psicóloga, Psicopedagoga, Mestranda em Psicologia na UFSC

** Doutora em Psicologia / UFSC

*** Psicóloga Residente na Universidade do Planalto Catarinense 